\title{
Dementia Research Australia: the Australian Dementia Research Development Fellowship Program
}

\author{
Ashley I. Bush ${ }^{1} \cdot$ George Fink $^{1} \cdot$ Peng Lei ${ }^{1,2}$
}

Published online: 6 October 2016

(C) Springer Science+Business Media New York 2016

Dementia affects hundred millions of people worldwide, and with no disease-modifying treatment for any form of dementia, the disease burden is worsening. Accelerating innovation in the diagnosis, prevention, treatment, and management of dementia (including its most prevalent form, Alzheimer's disease, $\mathrm{AD}$ ) is a global priority.

In Australia, dementia is now the second leading cause of death. Over 320,000 Australians are living with dementia, including one in four Australians over the age of 85. Deaths due to dementia have increased approximately $137 \%$ over the last 10 years, with nearly 11,000 deaths recorded in 2013 . The increasing prevalence is placing a growing emotional and financial burden on patients, their families, and friends. By 2050, it is estimated that nearly one million Australians will have dementia, and 7500 Australians will be diagnosed each week, with a far greater number living with this progressive disabling condition.

The Australian government announced as part of the 2014 budget an additional $\$ 200$ million over 5 years to boost Australia's dementia research capacity. In concordance with this initiative, the National Health and Medical Research Council (NHMRC), working in close collaboration with the

Ashley I. Bush

ashley.bush@ florey.edu.au

George Fink

george.fink@florey.edu.au

Peng Lei

peng.lei@scu.edu.cn; peng.lei@ florey.edu.au

1 Florey Institute of Neuroscience and Mental Health, The University of Melbourne, Parkville, VIC 3010, Australia

2 Department of Neurology, State Key Laboratory of Biotherapy, West China Hospital and Collaborative Innovation Center for Biotherapy, Sichuan University, Sichuan 610041, China
Australian Research Council (ARC), launched a joint NHMRC-ARC Dementia Research Development Fellowships Scheme on 8 January 2015 as part of the "Building the workforce" element of the Boosting Dementia Research Initiative. The aims of the scheme were to support the best emerging dementia researchers and attract scientists into dementia research from other fields, such as neurobiology, immunology, chemistry, bioengineering, information and communications technology, genomics, epidemiology, and cell and vascular biology. Applications were peer reviewed by expert panels against the dementia priority framework based on national and international strategies spanning primary prevention, secondary prevention, treatment, and quality of life and care. As a consequence, Dementia Research Development Fellowships were awarded for the most promising projects.

The present issue of the Journal of Molecular Neuroscience is comprised of cutting-edge review articles written by individual Dementia Research Development Fellows and their colleagues. This issue provides a comprehensive peer-reviewed, state-of-the-art account of dementia and related neurodegenerative disorders ranging from clinical, brain imaging, molecular biological mechanisms, and potential therapeutic targets, and covers all major forms of dementia, including $\mathrm{AD}$, vascular dementia, dementia with Lewy bodies, frontotemporal lobar degeneration, and Parkinson's disease dementia.

In this issue, a collection of articles were chosen to discuss important proteins and other biological factors involved in dementia, including tau protein ( $\mathrm{Li}$ et al. 2016), apolipoprotein E (ApoE ع4, Mahoney-Sanchez et al. 2016), BACE1 (Munro et al. 2016), presenilin (Greenough 2016), metals (McAllum and Finkelstein 2016), and gonadal hormone (Du and Hill 2016). In addition to neurons, the potential involvement of microglia in AD is discussed (Grubman et al. 2016). A second 
set of articles presented novel tools that can be used in dementia study, from clinically available magnetic resonance imaging (Yassi et al. 2016), the Cogstate Brief Battery (Lim et al. 2016), to a more under experimental development touchscreen platform for cognitive testing (Shepherd et al. 2016) and fluorescent nanoparticles to deliver drugs (Shimoni et al. 2016). Lastly, this issue also covers clinical findings relevant to dementia, including age-related prevalence of ApoE $\varepsilon 4$ in $A D$ (Heffernan et al. 2016), the potential to utilizing subjective cognitive decline for AD clinical trial (Buckley et al. 2016), and linkage between cognitive decline and alcohol abuse (Perry 2016).

Australia has a proud history of participation in dementia research (especially Alzheimer's disease), with an Australian, Colin Masters, being one of the first to complete the sequence of beta-amyloid which is still the main therapeutic target for $\mathrm{AD}$ (Masters et al. 1985) and the first to clone the amyloid protein precursor gene (Kang et al. 1987). With the Boosting Dementia Research Initiative, we hope to maintain the leadership of Australia in dementia research.

\section{References}

Buckley RF, Villemagne VL, Masters CL et al (2016) A conceptualization of the utility of subjective cognitive decline in clinical trials of preclinical Alzheimer's disease. J Mol Neurosci. doi:10.1007/s12031-016-0810-Z

Du X, Hill RA (2016) The potential of gonadal hormone signalling pathways as therapeutics for dementia. J Mol Neurosci. doi:10.1007/s12031-016-0813-9

Greenough MA (2016) The role of presenilin in protein trafficking and degradation -implications for metal homeostasis. J Mol Neurosci. doi:10.1007/s12031-016-0826-4

Grubman A, Kanninen KM, Malm T (2016) Multitasking microglia and Alzheimer's disease: diversity, tools and therapeutic targets. J Mol Neurosci. doi:10.1007/s12031-016-0825-5
Heffernan AL, Chidgey C, Peng P, Masters CL, Roberts BR (2016) The neurobiology and age-related prevalence of the $\varepsilon 4$ allele of apolipoprotein e in Alzheimer's disease cohorts. J Mol Neurosci. doi:10.1007/s12031-016-0804-X

Kang J, Lemaire HG, Unterbeck A, Salbaum JM, Masters CL, Grzeschik KH, Multhaup G, Beyreuther K, Muller-Hill B (1987) The precursor of Alzheimer's disease amyloid A4 protein resembles a cell-surface receptor. Nature 325:733-736.

Li X, James S, Lei P (2016) Interactions between $\alpha$-synuclein and tau protein: implications to neurodegenerative disorders. J Mol Neurosci. doi:10.1007/s12031-016-0829-1

Lim YY, Villemagne VL, Laws SM et al (2016) Performance on the cogstate brief battery is related to amyloid levels and hippocampal volume in very mild dementia. J Mol Neurosci. doi:10.1007/s12031-016-0822-8

Mahoney-Sanchez L, Belaidi AA, Bush AI, Ayton S (2016) The complex role of apolipoprotein e in Alzheimer's disease: an overview and update. J Mol Neurosci. doi:10.1007/s12031-016-0839-Z

Masters CL, Simms G, Weinman NA, Multhaup G, McDonald BL, Beyreuther K (1985) Amyloid plaque core protein in Alzheimer disease and down syndrome. Proc Natl Acad Sci U S A 82:42454249

McAllum EJ, Finkelstein DI (2016) Metals in Alzheimer's and parkinson's disease: relevance to dementia with lewy bodies. J Mol Neurosci. doi:10.1007/s12031-016-0809-5

Munro KM, Nash A, Pigoni M, Lichtenthaler SF, Gunnersen JM (2016) Functions of the Alzheimer's disease protease bace1 at the synapse in the central nervous system. J Mol Neurosci. doi:10.1007/s12031016-0800-1

Perry CJ (2016) Cognitive decline and recovery in alcohol abuse. J Mol Neurosci. doi:10.1007/s12031-016-0798-4

Shimoni O, Shi B, Adlard PA, Bush AI (2016) Delivery of fluorescent nanoparticles to the brain. J Mol Neurosci. doi:10.1007/s12031016-0833-5

Shepherd A, Tyebji S, Hannan AJ, Burrows EL (2016) Translational assays for assessment of cognition in rodent models of Alzheimer's disease and dementia. J Mol Neurosci. doi:10.1007/s12031-016-0837-1

Yassi N, Desmond PM, Masters CL (2016) Magnetic resonance imaging of vascular contributions to cognitive impairment and dementia. J Mol Neurosci. doi:10.1007/s12031-016-0799-3 